\title{
Design a scale of teaching competencies for students teachers in faculties of physical education.
}

브르르르르르르를

\section{* Assistant Professor/ Taha Sobhy Taha ** Assistant Professor/Mohsen Mohammed Saltah}

\section{Introduction}

Preparation of physical education teachers has many objectives , it should for the future teacher to get specialized content and have the ability to apply it ,also students teachers should learn how to use techniques and how to get skill which enables them to transfer the content for learner by sophisticated way and should have the sensitivity to students' diversity and curricula. and dealing with the student in all situation ( $6: 31$ ). The success of physical education teachers depends on preparation before graduation, so field training faculties of physical education is very important stage in programs of physical education teacher's preparation, the field training is considered as expedient by which theoretical and practical knowledge are mixed with reality of teaching in school, so the field training is the most important part in incorporation of teaching , and it is considered as the most effective in helping the students to turn up from theoretical to applied knowledge.( $22: 11)$. Student teacher turns up from position of student to position of teacher in period of training field ,which happens gradually under care of supervisor, who helps in developing the occupational skills .the student is assessed during the period of field training under certain rules and standards, by evaluating the occupational skills, which is important to create an efficient teacher . and find out extent of benefit for student after theoretical preparation on educational, psychological and academic fields in faculty, $(5: 43)$. The assessment process helps the supervisor in evaluating his students and finding their weaknesses and power points in teaching performance, and if they reached the program's specific goals. It also guides him to search for certain methods up to reach better training for student . the importance of student teacher assessment is through information about the degree of progress to reach specific goal and showing weaknesses and power points. $(20: 43)$. 
* Lecturer at School Sports Department in the Faculty of Physical Education for Men Alexandria University.

** Lecturer at School Sports Department in the Faculty of Physical Education for Men Alexandria University

The researcher believed that teaching performance competencies' evaluation for students teachers during the period of. field training is considered as final evaluation for all theoretical and applied efforts which student teacher had received during his study.also the assessment of teaching performance competency includes confirmation of doing teaching exercises practically before graduation, so the availability of objective scale for teaching performance competency should be present .

\section{-research problem}

The reliance on self assessment in issuing decisions about performance of student teacher through the period of external training field was noticed in supervision's field .so the researchers thought to find new method to avoid self assessment by creation of objective scale for teaching performance competency of students teachers. this objective scale maintains objective evaluation and cancels the doubt in evaluation grading, the researcher scan most of studies that talk about efficiency and teaching competencies :as study of Tawfiq Marei(1981) (2) which aim to determine the teaching performance competencies for teacher of elementary school in Jordon under light of system analysis and proposed program .while the study of Zainab abu enein (1990)(4) aimed to study some personal and practical aspect of qualified teachers .As for the study of Nadia Zaghloul (2000)(23) determination of the relationship between the creative thinking and some personality traits in level of performance in field training .as for Fathi Rashid (2002) (12),the study aimed to evaluate performance efficiency of physical education teacher in first stage of main education in governorate of Alexandria as for Abdul Majid Abdallah (2004)(8),study aimed to determine the necessary teaching skills for classroom teachers. While the study of Majida Kambsh (2011)(15) aimed to determine the teacher's competences for teacher of physical education. While the study of Ali Saleh(2002)(11), aimed to create performance and professional competencies for kindergarten teacher. while Lamia Ibrahim(2002)(14) her study aimed to the effect of using the educational bag on performing efficiency for the female student teacher in physical education 's lesson. as for Mustafa Ahmed 
(1994)(21),the study aimed to design the performance evaluation card for physical education teachers in the presence of teaching competencies, the researcher noticed that the study of Nadia Zaghloul (2000)(23):relied on the teaching competencies for teacher and its uses in evaluating teaching competencies of students teachers who are less in performance than teachers. also the study of Zainab Abu Enein (1990)(4), Fathi Rashid (2002)(12), Ali Muhammad Saleh(2002)(11), Lamia Ibrahim(2002)(14)addressed the teaching efficiency with rising level than the teaching competency, as for the study of Tawfiq Marei (1981)(2)\& Abdul Majid Ahmed (2004)(8) \& Majida Hamid Kambsh(2011) (15), Mustafa Ahmed (1994)(21),the study addressed the teaching competencies for teacher which are not suitable for students teachers, the researchers are believing that a scale of teaching efficiencies and teaching competencies for teachers who are in service, is not suitable for for the performance level of students teachers during the period of field training, So the researcher are prompted to design a scale for teaching competencies for students teachers in faculty of physical education.

\section{-Research aim :}

- Designation of ascale for teaching competencies for students teachers in faculties of physical education.

\section{-Research Terms:}

- Difference between competency and efficiency: competency achieves the lower limit goals, while efficiency achieves the upper limit of goals, therefore performance competencies for the teacher represent the lower limit of skills that must be acquired during preparing him pre-service or in while in service in order to achieve the desired teaching goals and these skills are measured only by observing his performance in the classroom through note cards prepared for this purpose. (10:57)

-Teaching competency: Kamal al-Din Hashim (2004) defines teaching competency as it is the teacher's ability to use compounded group of knowledge, patterns of behavior and skills while performing his

teaching role with same degree of specified workmanship.(13:17)

-Procedural definition of teaching competencies of students teachers: it is a set of attributes, knowledge, skills and attitudes that must be 
owned by students teachers of faculties of physical education to achieve the desired teaching goals. (researchers).

\section{Research Procedures}

- First, research methodology: the researcher used the descriptive approach because of its appropriateness for the nature of the research.

- Second, Society and research Sample: the community of the research included(29)professors of academic staff members in faculty of physical education for men- Alexandria university in the academic year (2014-2015) \& also the supervisor on the student teachers in external field (attachment number 5)

\section{- Creation of a scale for teaching competencies for students teachers in faculties of physical education.}

- Form of teaching competency for students teachers in the faculty of physical education. In order to design this form the researcher reviewed references and studies of thi topic $(1,2,4,7,8,9,10,12,16,17$, 18).

- The overall objective of this form was to measure the level of the teaching competency of the students during field training.

-In the overall objective, six axes were identified : first : competency of personality traits, second axis: competency of planning and preparing lessons, third axis: competency of implementation of lessons, fourth axis: competency of the use of teaching aids and tools, fifth axis: competency of classroom management ,sixth axis: competency of evaluation.

-The form of the six axes has been presented on (29) professors of academic staff members in faculty of physical education who are supervisors on students teachers in external field training. Attachment number (4) is to identify the appropriateness of axes to measure the performing skills of students teachers in the faculty of physical education, and It's clear from table (1). 
Table (1) approval rate of experts on the axes of the teaching competencies for students teachers) $n=29$

\begin{tabular}{|c|c|c|c|c|c|c|c|}
\hline \multirow[b]{2}{*}{ Axes } & \multicolumn{2}{|r|}{ dis agree } & \multicolumn{2}{|c|}{ agree to some extent } & \multicolumn{2}{|c|}{ disagree } & \multirow{2}{*}{$\begin{array}{c}\text { totality } \\
\text { of } \\
\text { approval } \\
\text { rate }\end{array}$} \\
\hline & Repetition & Percentage & Repetition & Percentage & Repetition & Percentage & \\
\hline $\begin{array}{l}\text { First Axis: Personality } \\
\text { Characteristics }\end{array}$ & 26 & 89.66 & 2 & 6.90 & 1 & 3.45 & 93.10 \\
\hline $\begin{array}{l}\text { Second Axis: Planning and } \\
\text { Preparing Lessons }\end{array}$ & 25 & 86.21 & 2 & 6.90 & 2 & 6.90 & 89.66 \\
\hline $\begin{array}{l}\text { Third Axis: Implementation } \\
\text { of Lessons }\end{array}$ & 27 & 93.10 & 1 & 3.45 & 1 & 3.45 & 94.83 \\
\hline $\begin{array}{l}\text { Forth :Axis Classroom } \\
\text { management Competency. }\end{array}$ & 14 & 48.27 & 3 & 10.34 & 12 & 41.37 & 58.61 \\
\hline $\begin{array}{l}\text { Fifth Axis: Using Teaching } \\
\text { Aids and Tools }\end{array}$ & 25 & 86.21 & 2 & 6.90 & 2 & 6.90 & 89.66 \\
\hline Sixth Axis: Evaluation & 26 & 89.66 & 2 & 6.90 & 1 & 3.45 & 93.10 \\
\hline
\end{tabular}

It's clear from Table (1) approval rate of experts on the axes of the teaching competencies for students teachers ranged from (58.61-94.83\%).

- The fourth axis was excluded :competency of classroom management's approval rate was less than the acceptance limit because of the acceptance limit is (70\%) so number of axes became (5)

- After the approval of experts on the scale 's axes, the researcher suggested new statements under each axis ,after referring to most of references and studies related to the topic $(1,3,2,4,7,8,9,10,12,16,17$, $18,19,22$ ).

-The total numbers of statements are 51 are representing the teaching competency for student teacher in faculty of physical education, which are being distributed on main 5 axes attachment (2)

\section{- Scientific coefficients:}

\section{1- scale trueness:}

a- trueness of Internal consistency: it is concluded from judges' trueness by showing the scale 's axes and statements attachment number (2)

- Also the six axes which are shown on same(29) experts to know an appropriateness of statements which represent any axis.

- The researchers' approval (70\%) as lower limit of acceptance of axes and statements.

- Statements number $(1,2)$ of second axis ,number $(12,15)$ of third 
axis, number (7) of fourth axis and number 3 of the fifth axis all were deleted to reach the acceptance ratio $70 \%$ of experts' opinion

- So the total number of application 's statements are 45 \& Attachment (6) is showing that.

b- trueness of discrimination: for judging on the scale 's truth, the researchers used the true discrimination on sample of (20) students teachers in the fourth year (specialized in teaching) in faculty of Physical Education for Men- Alexandria University , which contain (10) student are high level \&(10)student are less in teaching competences, Attachment (7) is showing that.

\section{2- The reliability:}

The reliability confirmation of the scale was done by retest on sample of (20) students teachers of students of fourth year. Attachment (8) is showing that.

\section{3-the objectivity:}

the objectivity confirmation of the scale was done by finding the correlation between degrees of two judgers on sample of (20) students teachers of fourth year, attachment (9) is showing that.

\section{- scale application:}

-The Researchers applied the scale on Sample (120) teacher student from fourth year in teaching division From Faculty of Physical education for boys- Alexandria university, to find the standard levels and Percent Standard.

- Researcher depends on the lessons recorded in video tapes and submitted by the students of the research's community as year work of the courses, where each student presented (video) tape for his performance during teaching a lesson of gymnastics for first middle grade students. In addition to the planning model of this lesson, this is implemented by the student during the days of field training in the period from sunday $1 / 3$ to thurs day 12/03/2015.

- Video tapes were examined and videos of bad sound or image were excluded from the research sample.

-Videos and planning models of lessons of students of the research's sample (120 students) were collected in the period from 14/03/2015 until $27 / 03 / 2015$ for presenting on the judges. attachment 
- Three professors of faculty staff (specialized in teaching) judged the teaching performance competency through the form and videos of students.

- The average score of the three judges has been taken.

- The application of values orientations scale on the sample on Monday, 16/03/2015.

- statistical description of sample's data For applied scale of teaching competencies In the final shape, Table(2)

Table (2) statistical description of sample's data of axes of teaching competencies) $n=120$

\begin{tabular}{|l|c|c|c|c|c|c|c|}
\hline \hline \multirow{2}{*}{\multicolumn{1}{|c||}{ Variables }} & \multicolumn{7}{c|}{ Descriptive Statistics } \\
\cline { 2 - 9 } & Mean & Median & Minimum & Maximum & $\begin{array}{c}\text { Std. } \\
\text { Deviation }\end{array}$ & Kurtosis & Skewness \\
\hline \hline First Axis: Personality Characteristics & 29.05 & 30 & 9 & 40 & 6.01 & 0.70 & -0.96 \\
\hline $\begin{array}{l}\text { Second Axis: Planning and Preparing } \\
\text { Lessons }\end{array}$ & 25.13 & 27 & 7 & 34 & 5.82 & 0.29 & -0.94 \\
\hline Third Axis: Implementation of Lessons & 60.78 & 62 & 17 & 76 & 5.59 & 2.13 & 1.08 \\
\hline Forth Axis: Using Teaching Aids and Tools & 23.69 & 25 & 7 & 35 & 5.85 & 1.24 & -1.12 \\
\hline Fifth Axis: Evaluation & 17.48 & 18 & 6 & 27 & 5.07 & -0.26 & -0.64 \\
\hline \hline total of teaching competencies & 156.13 & 162 & 46 & 266 & 34.78 & 1.53 & -0.61 \\
\hline \hline
\end{tabular}

clear from Table (2) that buckling coefficients ranged from (-0.96 to -1.08), which confirms that the concluded results are close to moderation where the moderate values of buckling coefficients ranged in \pm 3 . And these values are close to zero. Also, Splaying coefficient ranged from (- 0.26 to 2.13 ), which confirms the homogeneity between the sample's members in the axes of teaching competencies.

\section{- The Percent Standard for Axes of teaching competencies .}

table (3) normative grades and initial grades for Scale axes.

\begin{tabular}{|c|c|c|c|c|c|c|c|}
\hline \multirow{2}{*}{\multicolumn{2}{|c|}{ nc }} & \multicolumn{6}{|c|}{ initial grades } \\
\hline & & $\begin{array}{c}\text { First Axis: } \\
\text { Personality } \\
\text { Characteristics }\end{array}$ & $\begin{array}{l}\text { Second Axis: } \\
\text { Planning and } \\
\text { Preparing } \\
\text { Lessons }\end{array}$ & $\begin{array}{l}\text { Third Axis: } \\
\text { Implementation } \\
\text { of Lessons }\end{array}$ & $\begin{array}{l}\text { Forth Axis: } \\
\text { Using Teaching } \\
\text { Aids and Tools }\end{array}$ & $\begin{array}{l}\text { Fifth Axis: } \\
\text { Evaluation }\end{array}$ & $\begin{array}{c}\text { total of } \\
\text { teaching } \\
\text { competencies }\end{array}$ \\
\hline \multirow{9}{*}{$\begin{array}{l}\text { normative } \\
\text { grades }\end{array}$} & 10 & 20 & 16 & 40.2 & 16 & 9.2 & 103.2 \\
\hline & 20 & 24 & 20 & 51 & 21 & 13 & 134.4 \\
\hline & 30 & 27 & 23 & 57 & 22 & 15 & 148 \\
\hline & 40 & 29 & 25 & 60 & 24 & 18 & 155 \\
\hline & 50 & 30 & 27 & 62 & 25 & 18 & 162 \\
\hline & 60 & 32 & 28 & 64 & 26 & 20 & 167 \\
\hline & 70 & 33 & 29 & 67 & 27 & 21 & 176 \\
\hline & 80 & 34 & 30 & 69 & 28 & 21 & 181.6 \\
\hline & 90 & 36 & 32 & 71.5 & 30 & 23 & 189.8 \\
\hline
\end{tabular}


clear from Table (3) that total of axes of teaching competencies ranged in (103.2 to 189.8).

\section{- The Standard levels for Scale of teaching competencies for Student teachers.}

table (4) Standard levels and initial grades for Axes of teaching competencies for Student teachers

\begin{tabular}{|c|c|c|c|c|c|c|c|}
\hline \multirow{2}{*}{\multicolumn{2}{|c|}{ initial grades }} & \multicolumn{6}{|c|}{ initial grades } \\
\hline & & $\begin{array}{c}\text { First Axis: } \\
\text { Personality } \\
\text { Characteristics }\end{array}$ & $\begin{array}{l}\text { Second Axis: } \\
\text { Planning and } \\
\text { Preparing } \\
\text { Lessons }\end{array}$ & $\begin{array}{l}\text { Third Axis: } \\
\text { Implementation } \\
\text { of Lessons }\end{array}$ & $\begin{array}{l}\text { Forth Axis: } \\
\text { Using } \\
\text { Teaching Aids } \\
\text { and Tools }\end{array}$ & $\begin{array}{l}\text { Fifth Axis: } \\
\text { Evaluation }\end{array}$ & $\begin{array}{c}\text { total of } \\
\text { teaching } \\
\text { competencies }\end{array}$ \\
\hline \multirow{3}{*}{$\begin{array}{l}\text { Standard } \\
\text { levels }\end{array}$} & Low & 26 & 21 & 56 & 21 & 14 & 143.5 \\
\hline & medium & 30 & 27 & 62 & 25 & 18 & 162 \\
\hline & High & 34 & 30 & 68 & 28 & 21 & 180 \\
\hline
\end{tabular}

clear from Table (4) that the value of Low level in the Standard levels for Scale of teaching competencies for students teachers (143.5), the value of medium level (162), the value of High level (180).

\section{- Conclusions}

1-The scale of teaching competences for students teachers in faculty of Physical Education for Men- Alexandria University consists of (45) statement was distributed in 5 axes : first axis :personality characteristics(8 statement) ,second axis : planning \&preparing lessons ( 7 statement ), third axis :implementations of lessons (17 statement), fourth axis: using teaching aids \&tools (7 statement ), fifth axis :evaluation ( 6 statement).

2 - the suggested scale is characterized by honesty , stability and objectivity.

\section{- Recommendations}

1-using the scale in evaluation of teaching competencies for students teachers in faculty of physical.

2-making researches for preparation of teaching competencies for students teachers in different studying specialty .

\section{- References}

1- Tahany Abdul Aziz (2001): teaching skills and their relationship and commitment to the excellence in the field training in the physical education faculties for students teachers, published research, Journal of Science of Physical Education, thirteen editions, Part I, November. 
2- Tawfiq Ahmed Marei (1981): teaching performance competencies for teacher of elementary schools in Jordan in light of systems analysis and proposed a program, unpublished master thesis, faculty of education, Ain Shams university.

3-. Zainab Omar, Ghada Galal Abdel Hakim (2008): methods of teaching physical education and theoretical foundations and practical applications, the Arab Thought House, Cairo.

4- Zainab Mahmoud Abu Enein (1990): Some personal and practical aspects of qualified teaching staff for teachers, teaching and mental magazine, First Issue, sixth year, Menoufia University, 1990.

5-samiat frghla, nadiat Muhammad(2002) Field training in physical education, Dar al-Hikma library, Alexandria.

6- Abbas Ahmed alSamarrai, AbdulKarim Mahmoud alSamarrai(1991): Teaching comptences in Methods of Teaching Physical Education, Baghdad University.

7- Abdullah Omar al-Farra and Abdul Rahman Abdul Salam Jamal (2003): Modern leader in the practical education and teaching, part 1, house of culture for publishing and distribution, Amman.

8- Abdul Majid Ahmed Abdallah (2004): necessary teaching skills for classroom teachers, journal of teaching researches center, edition 5. El Baha university.

9- Ali Dairi and Imad Batayneh (2004): teaching competencies and the degree of practicing field training in the faculty of physical education, scientific eighth International congress of physical education and sports.

10- Ali rashid (2005), competencies of teaching performance part 1 , Dar El-Arab for thought, Cairo.

11- Ali Muhammad Saleh(2002): building competencies performance and professional list for kindergarten teachers which linked to motor growth, unpublished master's thesis, faculty of physical education, helwan university.

12- Fathi Yousef Rashid (2002): evaluating performance efficiency of the teacher of physical education, the first stage of main education in 
the governorate of Alexandria, unpublished $\mathrm{PhD}$ thesis, and faculty of physical education for men, alexandria university.

13- Kamal al-Din Hashim (2004): Teacher's competences in planning lessons - the implementation of the lessons - evaluation in teaching, el rushd library, riyadh.

14. Lamia Mohamed Ibrahim(2002): effective of using educational bag on Performing on efficiency, For student techer In physical education lesson unpublished Ph.D, faculty of physical education for girls, Helwan university.

15- Majida Hamid Kambsh(2011): teacher's competences for teachers of physical education, journal of physical education sciences, faculty of physical Education, diyala universitym, the first number volume $4^{\text {th }}$.

16- Magdy Mahmoud Fahim (2009): scientific and practical methods of teaching methods, first edition, fulfillment house to a minimum printing and publishing, Alexandria.

17-Mohammed Eldridge (2000): competencies in education to establish a scientific and curriculum shape, knowledge for all series, no. XVI, ramses for publishing, Rabat

18- Mohammed Eldridge (2003): purposeful teaching from teaching objectives to the teaching competencies model, book house, the Sultanate of Oman.

19- Mohamed Mohamed Shahat (2007): teaching physical education, Dar Al Arab Thought, Cairo.

20- Mahdi Mahmoud Salem, Abdul Latif Milky(1998): field of education and the basics of teaching, second edition, ela beikan library, Riyad.

21- Mustafa Ahmad Muhammad (1994) : design the evaluation card of performance of Physical Education Teacher, based on the efficiencies of teaching, assiut journal of science and arts of physical education, $5^{\text {th }}$ number, part one.

22- Makarem Helmi Abu Hrjh, Mohammed Saad Zaghloul and Radwan Mohammed Radwan (2000): encyclopedia of field training of physical education, 1st edition, book publishing center, Cairo.

23- Nadia Hassan Zaghloul (2000): relationship of creative thinking and some personality traits level of performance in field training, 
unpublished master thesis, faculty of physical education for girls, Zagazig university. 